\title{
calendar of meetings
}

\section{0}

London, England

Sept. 3-7

Engelberg, Switzerland

Sept. 17-21

Bogota, Colombia

Shanghai, People's

Rep. of China

Kananaskis Pk., Alta., Canada

Kananaskis Pk., Alta., Canada

Kananaskis Pk., Alta., Canada

Kananaskis Pk., Alta., Canada

Geneva, Switzerland

Salvador, Bahia, Brazil

San Francisco, Calif.

New Orleans, La.

New Orleans, La.

New Orleans, La.

New Orleans, La.

New Orleans, La.

Jan. 13-18

Sept. 17-21

Oct. 15-19

Oct. 22-26
*Fifth Conference on Satellite Meteorology and Oceanography (joint with RMS)

21st International Conference on Alpine Meteorology (ITAM-90)

*16th Conference on Severe Local Storms

${ }^{*}$ Special Session on Artificial Intelligence

${ }^{*}$ Eighth Conference on Hydrometeorology

${ }^{*}$ Conference on Atmospheric Electricity

Oct. 29-Nov. 7

Second World Climate Conference

Sixth Brazilian Meteorological Congress

${ }^{\#+}$ American Geophysical Union Fall Meeting

*71st AMS Annual Meeting

*Second Symposium on Global Change Studies

*Seventh AMS Symposium on Meteorological Observations and Instrumentation

*Seventh Joint Conference on Applications of Air Pollution Meteorology with AWMA

${ }^{*}$ Seventh International Conference on Interactive Information and Processing Systems for Meteorology, Oceanography, and Hydrology

\# New listing in Calendar

* Meeting administered by AMS; other meetings AMS cosponsors or cooperates

${ }^{+}$New listing — see Announcements/Calls for Papers 
New Orleans, La.

New Orleans, La.

College Station, Tex.

St. Petersburg, Fla.

Norman, Okla.

Missoula, Mont.

Chicago, Ill.

Miami, Fla.

Miami, Fla.

New Orleans, La.

Boulder, Colo.

London, England

Paris, France

Paris, France

Rolla, Mo.
Jan. 13-18

Jan. 13-18

Feb. 27-March 1

March 25-28

April 2-5

April 16-19

April 16-19

May 6-10

May 6-10

May 20-24

June 3-6

June 17-21

June 24-28

June 24-26

Summer
${ }^{*}$ First International Winter Storm Symposium

"Special Session on Laser Atmospheric Studies

III Conference on Modeling of Rainfall Fields: Hydrologic and Meteorological Aspects

Second Annual Meeting of The Oceanographic Society

Tornado Symposium III

11th Conference on Fire and Forest Meteorology

Third Topical Meeting on Emergency Preparedness and Response

*19th Conference on Hurricanes and Tropical Meteorology

*Fifth Conference on Meteorology and Oceanography of the Coastal Zone

International Conference and Workshop on Modeling and Mitigating the Consequences of Accidental Releases of Hazardous Materials

Symposium on the Tropospheric Chemistry of the Antarctic Region

${ }^{\#+}$ First International Conference on Broadcast Meteorology with the Royal Meteorological Society

*25th International Conference on Radar Meteorology

${ }^{*}$ Fourth International Conference on Aviation Weather Systems

International Workshop on Comparison of Condensation (Aitken) Nuclei and Aerosol Particle Counters

\# New listing in Calendar

${ }^{*}$ Meeting administered by AMS; other meetings AMS cosponsors or cooperates

${ }^{+}$New listing — see Announcements/Calls for Papers 
Richland, Wash.

July 15-19

Dublin, Ireland

July 22-26

Vienna, Austria

Aug. 11-24

Salt Lake City, Utah

Salt Lake City, Utah

Salt Lake City, Utah

Salt Lake City, Utah

Denver, Colo.

Denver, Colo.

Denver, Colo.

October

Sept. 10-13

Sept. 10-13

Sept. 10-13

October

October
Fifth International Conference on

Precipitation Scavenging and

Atmosphere-Surface Exchange Processes

13th IMACS World Congress on Computation and Applied Mathematics

IUGG XX General Assembly

"20th Conference on Agricultural and Forest Meteorology

"Special Session on Hydrometeorology

*Tenth Conference on Biometeorology and Aerobiology

*Seventh Conference on Applied Climatology

${ }^{*}$ Fifth Conference on Climate Variations

${ }^{*}$ Eighth Conference on Atmospheric and Oceanic Waves and Stability

"Ninth Conference on Numerical Weather Prediction

\# New listing in Calendar

${ }^{*}$ Meeting administered by AMS; other meetings AMS cosponsors or cooperates

+ New listing--see Announcements/Call for Papers

\section{Meeting Procedures for Authors (for meetings administered by AMS)}

A change in AMS procedures: Only authors who send payment or a purchase order to AMS headquarters will be preregistered for meetings (this includes committee members and program/session chairpersons).

When submitting an abstract, the principal speaker (we assume the principal speaker is the first author) must indicate his/her address, telephone and fax numbers, and electronic mailbox (if available). We assume the speaker is our principal contact. If the speaker is not the principal contact, please list the name, address, telephone number, etc., of the person who will be.

For meetings that have preprint or extended abstracts volumes, only reviewer's abstracts will be required; abstracts will not be published in the BULLETIN.

For meetings that do not have preprint or extended abstracts volumes, both reviewer's abstracts and short abstracts (100 words) for inclusion in an abstract booklet to be distributed at the meeting will be required.

Because of time constraints and escalating costs, AMS will no longer accommodate changes in authors' names, affiliations, paper titles, and/or abstracts once the program has been received at AMS from the program chairman.

Programs are now sent by computer. Mathematical/chemical equations and/or symbols may not be used in titles and short abstracts. Please substitute words, phrases, or sentences for mathematical and chemical expressions.

Authors are requested to comply with the above procedures. 


\section{Announcements}

\section{Fifth Conference on Satellite Meteorology and Oceanography, Sept. 3-7, 1990, London, England}

The Fifth Conference on Satellite Meteorology and Oceanography, jointly sponsored by the American Meteorological Society and the Royal Meteorological Society and cosponsored by the Royal Society and the World Meteorological Organization, will be held 37 September 1990 at the Royal Society, Carlton House Terrace, London, England. The Conference is also supported by EUMETSAT, British Aerospace, Software Sciences, British National Space Centre and the European Space Agency.

The technical program has been arranged jointly by the AMS Committee on Satellite Meteorology and Oceanography and the Royal Meteorological Society. This joint meeting will provide an opportunity for interaction between international organizations conducting research in satellite observations of the atmosphere and ocean.

Papers have been solicited on all aspects of satellite meteorology and oceanography, especially those that address international programs, new or anticipated satellite systems (e.g. AMSU, SSM/I, ERS1, GOES-Next, AVHRR-Next, EOS), new uses of "conventional" satellite data sets, global and climate scale analyses, and applications of satellite data in mesoscale analysis and nowcasting.

The deadline for abstracts has passed. Attendees will receive a preprint volume at the conference.

For further information, contact one of the Program Co-Chairpersons: Paul Twitchell, 509 Schley Rd., Annapolis, MD 21401 (tel.: 301-263-8976); or Chris Collier, Meteorological Office, Met 024 , London Road, Bracknell, Berkshire RG12 2SZ U.K. (tel.: 44-344856244; fax: 44-344-854412; telex: 849801). Or contact the Chairperson of the AMS Committee on Satellite Meteorology and Oceanography: Phil Durkee, Dept. of Meteorology, 63De, Naval Postgraduate School, Monterey, CA 93943 USA (tel.: 408-646-3465; fax: 408-646-3061).

The conference program was published in the May 1990 issue of the BULLETIN.

For information on registration and hotel accommodations, contact either the AMS or the Royal Meteorological Society, 104 Oxford Road, Reading, Berks, U.K. RG1 7LJ (tel.: 44-734-568500; fax: 44734-568571). (10/89; r2/90; r7/90)

Third International Conference on Atmospheric Sciences and Application to Air Quality (ASAAQ), Oct. 15-19, 1990, Shanghai, People's Rep. of China

The Third International Conference on Atmospheric Sciences and Application to Air Quality (ASAAQ) will take place 15-19 October 1990 in Shanghai, People's Rep. of China. The third conference in this series, which pays particular attention to the Pacific Rim area, will focus on urban air quality. The American Meteorological Society is a cooperating organization.

In addition to urban air quality, other topics to be explored include air quality meteorology; modeling atmospheric flow patterns; air/aerosol/cloud deposition /acid rain; measurement techniques; regional/global effects; atmospheric transport/dispersion; data presentation/interpretation; air quality modeling/ prediction; environmental impact assessment/decision making/policy/goal achievement; and impact of developing energy, industrial and agricultural technology on air quality/radiation/climate.

The deadline for abstracts has passed.

Special lectures to be given in Beijing during 2123 October, which also include tours of the Forbidden City, the Great Wall, etc., will be arranged by the Atmospheric Environment Section of the Chinese Society of Environmental Sciences. Participants from abroad who wish to give a lecture at the Beijing meeting should submit their plan to the Conference Secretariat. For further information, please refer to May and June issues of the BULLETIN. (4/90; r5/90)

16th Conference on Severe Local Storms, Oct. 22-26, 1990, Kananaskis Provincial Park, Alta., Canada

The 16th Conference on Severe Local Storms, organized by the American Meteorological Society and cosponsored by the Canadian Meteorological and Oceanographic Society and the American Geophysical Union, and with the cooperation of the Alberta Research Council, will be held 22-26 October 1990 at Kananaskis Provincial Park (40 miles from Banff), Alberta, Canada. The conference is being held in conjunction with the Eighth Conference on Hydrometeorology and the Conference on Atmospheric Electricity (see following announcements), and will be cosponsored by the associated AMS committees.

The Severe Local Storms Program Committee has welcomed a wide variety of papers on all aspects of severe local storms, including theoretical and numerical modeling and predictability investigations, observational studies, applications of new data types, and applied research in forecasting and operations. Topics of relevance include thunderstorms and related phenomena, mesoscale convective systems, flash floods, local aspects of winter storms, and mountaininduced wind storms. Papers that involve aspects of hydrometeorology and atmospheric electricity have been especially encouraged.

Oral and poster sessions are planned, including joint sessions with the Eighth Hydrometeorology and Atmospheric Electricity conferences, with invited review presentations scheduled at the beginning of selected sessions. Poster sessions will be of equal status to 
oral presentations. A banquet will be held during the conference, and two evenings will be devoted to presentations of severe storm photography and video, along with visual displays of severe local storm research that could not be shown during the formal sessions. Awards will be given for the best visual aids accompanying an oral presentation, the best poster display, and the best paper by a first-time presenter.

The deadline for abstracts has passed. Registrants will receive a preprint volume at the meeting.

The conference program was published in the June 1990 issue of the BULLETIN.

For further information, contact one of the following Program Co-Chairpersons: Dr. Kelvin Droegemeier, School of Meteorology, Univ. of Oklahoma, 200 Felgar St., Rm. 219, Norman, OK 73019 (tel.: 405-3256561); Dr. Robert Davies-Jones (tel.: 405-366-0419) or Dr. Charles Doswell (tel.: 405-321-2319), NOAA/ National Severe Storms Lab., 1313 Halley Circle, Norman, OK 73069. (9/89; r4/90)

\section{Special Session on Artificial Intelligence, Oct. 22-26, 1990, Kananaskis Provincial Park, Alta., Canada}

A Special Session on Artificial Intelligence is being planned as part of the 16th Conference on Severe Local Storms (see preceding announcement) to be held 22-26 October 1990 in Kananaskis Park (40 miles from Banff), Alta., Canada. The session is being organized by the newly-formed AMS Committee on Artificial Intelligence (AI) Applications to Environmental Science, chaired by Dr. William R. Moninger.

Because of the recent development and testing of Al systems that forecast convective storms, the Program Committee of the Severe Storms Conference has agreed to have the Al committee sponsor an Al session, pending a sufficient number of qualified papers. The Al committee has invited contributions from scientists who are applying $\mathrm{Al}$ to the problems of severe-storm forecasting.

The deadline for abstracts has passed. At the meeting, registrants will receive a preprint volume containing papers from the special Al session and the 16th Conference on Severe Local Storms.

The conference program is included in the 16th Conference on Severe Local Storms program, published in the June 1990 issue of the BULLETIN.

For further information about the session, contact either Dr. Moninger, NOAA/ERL, R/E/FS, 325 Broadway, Boulder, CO 80303 (tel.: 303-497-6435; fax:303-497-6014) or the Program Chairperson of the 16th Conference on Severe Local Storms, Dr. Kelvin Droegemeier, School of Meteorology, Univ. of Oklahoma, 200 Felgar St., Rm. 219, Norman, OK 73019 (tel.: 405-325-6561). (1/90; r4/90)
Eighth Conference on Hydrometeorology, Oct. 22-26, 1990, Kananaskis Provincial Park, Alta., Canada

The Eighth Conference on Hydrometeorology, sponsored by the American Meteorological Society, the American Water Resources Association, the American Society of Civil Engineers, the Canadian Meteorological and Oceanographic Society and the American Geophysical Union, and with the cooperation of the Alberta Research Council, will be held 22-26 October 1990 at Kananaskis Provincial Park (40 miles from Banff), Alberta, Canada. This conference is being held in conjunction with the 16th Conference on Severe Local Storms (see preceding announcement) and the Conference on Atmospheric Electricity (see following announcements). The meeting is being organized by the AMS Committee on Hydrology and is cosponsored by the associated AMS committees.

The deadline for abstracts has passed. Registrants will receive a preprint volume at the conference.

The conference program was published in the June 1990 issue of the BULLETIN.

For further information, contact the Program Chairperson, Dr. Konstantine P. Georgakakos, lowa Institute of Hydraulic Research, University of lowa, lowa City, IA 52245-1545 (tel.: 319-335-5222).(11/89; $\mathrm{r} 4 / 90$ )

Conference on Atmospheric Electricity, Oct. 22-26, 1990, Kananaskis Provincial Park, Alta., Canada

The Conference on Atmospheric Electricity, organized by the American Meteorological Society and cosponsored by the Canadian Meteorological and Oceanographic Society and the American Geophysical Union, and with the cooperation of the Alberta Research Council, will be held 22-26 October 1990 at Kananaskis Provincial Park (40 miles from Banff), Alberta, Canada. The meeting is being held in conjunction with the 16th Conference on Severe Local Storms and the Eighth Conference on Hydrometeorology (see preceding announcements).

The AMS Committee on Atmospheric Electricity has welcomed the submission of research papers dealing with all aspects of electrical phenomena in the atmosphere. Interdisciplinary papers dealing with lightning or storm electricity and their relation to the meteorological environment are especially relevant for presentation at thismeeting. This is the motivation for joining with the Severe Local Storms and Hydrometeorology Conferences (please see the preceding announcements).

The deadline for abstracts has passed. Registrants will receive a preprint volume at the meeting.

The conference program was published in the June 1990 issue of the BULLETIN.

For further information, contact the Program 
Chairperson, Dr. Vincent Idone, Department of Atmospheric Science, SUNY--Albany, 1400 Washington Ave., Albany, NY 12222 (tel.:518-442-4577; fax:518442-4753). (12/89; r4/90)

\section{Second World Climate Conference, October} 29-November 7, 1990, Geneva, Switzerland

The Second World Climate Conference will take place at the International Conference Center in Geneva, Switzerland from 29 October to 7 November 1990. Attendance will be by invitation on the basis of personal expertise, taking into account appropriate disciplinary and geographic representation.

The scientific technical part of the Conference will take place from 29 October to 3 November 1990 with sessions beginning at 8:45 am each day and ending approximately at 6:00 pm. The Ministerial Meeting will take place on the final two days, 6 and 7 November. Those attending the Ministerial Meeting will be Members of Delegations named by participating countries, observers designated by international agencies, and conference staff and resource people.

In general, participants will be responsible to bear their own costs. Some financial assistance is available for those from developing countries. The overall schedule for the conference was published in the June and July issues of the BULLETIN.

For further information, please contact Howard Ferguson at the World Meteorological Organization, P.O. Box 2300, CH-1211 Geneva 2, Switzerland (tel.: 41-22-730-8111, or fax: 41-22-734-2326). (6/90)

\section{Sixth Brazilian Meteorological Congress, Nov. 19-24, 1990, Salvador, Bahia, Brazil}

The Sixth Brazilian Meteorological Congress, sponsored by the Brazilian Meteorological Society, will be held 19-24 November 1990 at the Centro de Convencoes da Bahia in Salvador, Bahia, Brazil. The American Meteorological Society is a cooperating organization.

This conference will focus on the important role of the Amazon rainforest in the world environment. Both Portuguese and English will be the working languages of the congress.

Papers have been solicited on the following topics: tropical/extra-tropical interactions, ground-forestatmosphere exchanges, climate change and variability, tropical droughts, ENSO phenomenon, synoptic meteorology, numerical weather prediction in the tropics, climatology, agrometeorology, micrometeorology, solar and terrestrial radiation, instrumentation, data collection and processing systems, radar and satellite meteorology, and atmospheric chemistry. Sessions will be organized according to abstract submissions and will have the participation of invited speakers.

The deadline for abstracts has passed.

Authors of accepted papers will receive special instructions on submitting extended abstracts for publication in a preprint volume.

For further information, contact Mr. Silvio de Oliveira, President, Congress Technical-Scientific Commission, Rua Vitoria, 106--Santa Efigenia, 01210-Sao PauloSP, Brazil (tel.: 55-11-2233176; telex: 011-23575). (2/ $90 ; r 5 / 90)$

\section{American Geophysical Union Fall Meeting, Dec. 3-7, 1990, San Francisco, Calif.}

The Fall Meeting of the American Geophysical Union (AGU) will be held 3-7 December 1990 at the Civic Auditorium in San Francisco, California.

A number of special sessions are planned. Those of interest to our members include Atmospheric Sciences, Hydrology, Ocean Sciences and SolarPlanetary Relationships.

The deadline for abstracts was 6 September 1990. For information on sessions and abstracts, see the 26 June 1990 issue of AGU's Eos, or contact: 1990 Fall Meeting, American Geophysical Union, 2000 Florida Ave., NW, Washington, DC 20009, tel.: 202$462-6900$ or (toll-free) 800-966-2481. (9/90)

\section{Second Symposium on Global Change Studies, Jan. 13-18, 1991, New Orleans, La.} A Second Symposium on Global Change Studies, including a Panel on Environmental Science and Public Policy and a Panel on Environmental Science and Education, will be held 13-18 January 1991 at the Hyatt Regency Hotel in New Orleans, La. The Symposium will be held in conjunction with the 71st AMS Annual Meeting and concurrently with the Seventh Symposium on Meteorological Observations and Instrumentation, Seventh Joint Conference on Applications of Air Pollution Meteorology with AWMA, Seventh International Conference on Interactive Information and Processing Systems, First International Winter Storm Symposium and Special Session on Laser Atmospheric Studies. The American Geophysical Union, Association of American Geographers, Ecological Society of America, The Oceanographic Society, and the World Meteorological Organization are cosponsoring the Symposium.

The two invited panel discussions will address the public policy aspects and educational opportunities related to the increased research activities in the environmental sciences, including global and regional scale global change studies. The panel on Environmental Science and Public Policy will address the role of science in political debates, the treatment of uncertainty in data analyses and model projections, and the problems of integrating widely diverse model projections in policy assessments. The panel on Environmental Science and Education will address the use of observational data, computer models and state-of-the-art information presentation methods to enhance education in all three principal sectors: public, 
scholastic and university level.

The Symposium is being organized by AMS President James R. Mahoney to reflect the theme of The Environmental Decade chosen for the 71st Annual Meeting. The Program Committee will be chaired by Eric Barron (AMS Committee on Climate Variations), and will consist of John Merrill (AMS Committee on Chemistry), Robert Gurney (AMS Committee on Hydrology), Rolando Garcia (AMS Committee on the Middle Atmosphere), and David Houghton (AMS Education and Manpower Commission), in addition to the Chairpersons of the concurrent conferences listed in the related calls for papers.

Papers were solicited in the following technical areas: (1) "Mission to Planet Earth"/the Earth Observing System, (2) global and regional scale model evaluation and integration, (3) stratospheric ozone, and (4) measurement and archiving methods for very longterm trend monitoring. The program will also include some invited papers.

The deadline for abstracts has passed. AMS will provide instructions and special typing paper to authors of accepted abstracts. Complete, camera-ready manuscripts of not more than six pages in length, including diagrams, must be submitted not later than 15 October 1990 to AMS headquarters. Page charges will be assessed to defray printing costs. Registrants will receive a preprint volume at the meeting.

For more information on the Symposium and panels; contact Dr. Eric Barron, Earth Sys. Science Ctr., Penn State Univ., University Park, PA 16802 Attn: AMS Annual Mtg. (tel.: 814-865-1619; fax: 814865-3191) or Dr. James R. Mahoney, Director, National Acid Precipitation Assessment Program, 722 Jackson
Place, NW, Washington, DC 20503 (tel.: 202-3955771; fax: 202-395-3928). (5/90; r8/90)

\section{Seventh Symposium on Meteorological Observations and Instrumentation, Jan. 13-} 18, 1991, New Orleans, La.

The Seventh Symposium on Meteorological Observations and Instrumentation, sponsored by the American Meteorological Society and cosponsored by the World Meteorological Organization, will be held during the 71st AMS Annual Meeting, 13-18 January 1991, at the Hyatt Regency Hotel in New Orleans, La.

Papers were solicited on all aspects of observations in the atmosphere, including direct and remote instrumentation technology for meteorology and atmospheric chemistry, techniques of measurement, applications of in-situ monitoring, results from observational studies, and observational requirements of proposed field studies.

Invited papers will be presented on various aspects of observations in the atmosphere. A panel discussion is being proposed that will focus on observational requirements for studies of global change. There is also the possibility of joint sessions with the Special Session on Laser Atmospheric Studies. Facilities will be available for exhibits of meteorological equipment.

AMS will provide instructions, deadline information, and camera-ready paper to authors of accepted papers. Page charges will be assessed to defray printing costs. A volume of extended abstracts will be distributed at the meeting.

For further information, contact the Program Chairperson, C. Bruce Baker, MD-80, U.S. EPA,

\section{SCHOLARSHIP}

Stipends will be available to cover air travel, hotel accommodations and registration for a limited number of graduate students attending the Second Symposium on Global Change Studies. Eligible candidates must be full-time graduate students enrolled in a department dealing with earth, geophysical, or physical/chemical/biological sciences at an accredited university. While preference will be given to student members of the sponsoring societies (American Meteorological Society, American Geophysical Union, Association of American Geographers Ecological Society of America, The Oceanographic Society and the World Meteorological Organization), nonmember candidates may be selected if they demonstrate a strong interest in earth sciences.

Each candidate must have a faculty sponsor who is a member of the department in which the student is doing graduate study. The sponsor will read the student's two-page application and fill in page three. It is hoped that the sponsor will be able to aid the student in covering expenses for meals, ground transportation and incidentals. The sponsor is encouraged to attend the symposium.

To obtain an application form and instructions, write to the American Meteorological Society, Attn.: Evelyn Mazur, 45 Beacon St., Boston, MA 02108 (tel: 617-227-2425; fax: 617-742-8718).

Mail the completed forms to Dr. Eric J. Barron, Earth System Science Center, 512 Deike Bldg., Penn State Univ., University Park, PA 16802 (tel.: 814-865-1619). Applications must be received no later than 12 October 1990.

Applications will be reviewed by the symposium program committee. Each applicant will be notified of the committee's decision by the end of November, 1990. A waiting list also will be compiled should students selected be unable to attend the symposium. 
Research Triangle Park, NC 27711 (tel.: 919-5414564). (9/89; r12/89)

\section{Seventh Joint Conference on Applications of} Air Pollution Meteorology with AWMA, Jan. 13-18, 1991, New Orleans, La.

The Seventh Joint Conference on Applications of Air Pollution Meteorology, cosponsored by the American Meteorological Society and the Air and Waste Management Association, will be held 13-18 January 1991 at the Hyatt Regency hotel in New Orleans, La. The conference is being held in conjunction with the 71st AMS Annual Meeting, the theme of which is the "Environmental Decade."

Papers were solicited on the following topics: (1) meteorological aspects of acid deposition and photochemical oxidants; (2) global climate effects on local and regional air quality; (3) advances in measurement technology for air pollutants and meteorology; (4) meteorology of air pollution episodes and extreme events; (5) role of clouds and fog in air pollution; (6) complex terrain model development and evaluation; (7) urban air quality model development and evaluation; (8) regional to long-range transport studies; (9) spatial and temporal evolution of mixed layer depths; and (10) advanced stack plume modeling techniques.

Sessions will include oral presentations, a few invited papers, and poster sessions. Brief oral summaries of the posters will be made during regular sessions. A special panel will review the results of the NAPAP acid deposition model assessment efforts. There is also the possibility of joint sessions with the Special Session on Laser Atmospheric Studies.

The deadline for abstracts has passed. Complete,

camera-ready manuscripts not more than six pages in length, including diagrams, must be submitted not later than 22 September 1990 to AMS headquarters, Attn.: Evelyn Mazur, 45 Beacon St., Boston, MA 02108 (tel.:617-227-2425; fax:617-742-8718). Page charges will be assessed to defray printing costs. Registrants will receive a preprint volume at the meeting.

For further information about the conference, contact either Dr. Jason Ching, ASMD/AREAL, MD80, U.S. EPA, Research Triangle Park, NC 27711 (tel.: 919-541-4801; fax: 919-541-1379) or Joseph Laznow, Research-Cottrell Co., U.S. Highway 22 West, Branchburg, NJ 08876 (tel.:201-685-4871). (1/ 90; r2/90; r6/90)

Seventh International Conference on Interactive Information and Processing Systems (IIPS) for Meteorology, Oceanography, and Hydrology, Jan. 13-18, 1991, New Orleans, La.

The Seventh International Conference on Interactive Information and Processing Systems (IIPS) for Meteorology, Oceanography, and Hydrology, sponsored by the American Meteorological Society, will be held 13-18 January 1991 at the Hyatt Regency hotel in New Orleans, La., in conjunction with the 71st AMS Annual Meeting. The Seventh IIPS Conference is cosponsored by the World Meteorological Organization (WMO), the Joint Oceanographics Institutions (JOI), the American Water Resources Association (AWRA), and the Association of American Geographers (AAG).

This applied interactive technology conference brings together the government and private sectors both international and national, and those who supply or use data and information systems and technology.

The conference will include exhibits and demonstrations which continue to be popular and help to illustrate the practicality of using off-the-shelf, demonstrated marketable systems and software tailored to meet the needs of meteorology, oceanography, and hydrology. Potential exhibitors should contact Yale Schiffman, Exhibits Manager, American Meteorological Society, 1755 Massachusetts Ave. N.W., Suite 700, Washington, DC 20036 (tel.: 202-234-2717; fax: 202234-9538).

Special activities this year will include a tutorial on Geographic Information Systems (GIS) to be held Monday afternoon. A special session on GIS will be held on Wednesday, and a session on satellite technology will be held on Thursday. PROFS again plans to give live weather briefings Tuesday, Wednesday and Thursday mornings. The GIS session will be organized by Brent Yarnel (814-863-4894; fax: 814865-3191) at Penn State, and the satellite session by Russell Koffler at the NOAA Satellite Service (301763-7190). Charles Nethaway of the U.S. Geological Survey (703-648-5656) will be organizing a session on hydrology. Bill Schramm is organizing a session on ocean technology (408-646-1649), and James Schiavone (201-949-5624) is arranging a tutorial on human factors and visualization, time and date tba.

$\mathrm{PC}$ and compatibles, $\mathrm{PS} / 2$ and Macintosh personal computers will be provided for the electronic posters, and presenters are encouraged to use them. Portables provided by presenters are welcome. Large-screen video projection for on-line, computer-driven color (RGB) digital systems with resolutions of $640 \times 512$ and $1280 \times 1024$ will be provided for presentations. Use of VHS and 3/4" U-Matic cassettes for television also is encouraged. Those who wish to use these systems must indicate their intentions in their abstracts.

The deadline for abstracts has passed.

AMS will provide instructions and special paper to authors of accepted abstracts. Complete, cameraready manuscripts not more than eight pages in length, including photos and diagrams, must be submitted not later than 1 October 1990 to AMS headquarters, Attn.: Evelyn Mazur, 45 Beacon St., Boston, MA 02108 (tel.: 617-227-2425; fax: 617-7428718). Page charges and any additional charges for photo processing will be assessed to defray printing costs. Registrants will receive a preprint volume at the conference. 
For further information, contact the Conference Co-Chairperson, G. Stanley Doore, 2913 Shanandale Drive, Silver Spring, MD 20904-1822 (tel.: 301-5724939; fax: 301-572-9165). (1/90; r5/90)

First International Winter Storm Symposium, Jan. 13-18, 1991, New Orleans, La.

The First International Winter Storm Symposium, sponsored by the American Meteorological Society, will be held during the 71st AMS Annual Meeting, 1318 January 1991, at the Hyatt Regency Hotel in New Orleans, La.

The goal of this symposium is to review recent progress in understanding of winter storms, particularly the life cycle of midlatitude cyclones and the associated scale interactions. Comparison of theoretical, modeling and field observation studies with operational numerical weather prediction performance will provide the opportunity to assess our understanding and clarify the outstanding issues.

Scientific sessions, including reviews, will focus on: theory of cyclone life cycle, interaction of cyclones with planetary waves, interactions of cyclones with fronts and precipitation processes, oceanic cyclones, fronts and ocean response, continental and orographic influences on cyclones. It is expected that scientific sessions will include contributions on prediction performance demonstrated at national centers, recent field studies including GALE, CASP, Ocean Storms, FRONTS and ERICA and studies of the recent violent storms in western Europe. Remaining problems will be compared with plans for the upcoming decade-long STORM Program.

The deadline for abstracts has passed. AMS will provide instructions and special typing paper to authors of accepted abstracts. Complete, camera-ready manuscripts not more than six pages in length, including diagrams, must be submitted not later than 1 October 1990 to AMS headquarters, Attn.: Evelyn Mazur, 45 Beacon St., Boston, MA 02108 (tel.: 617227-2425; fax: 617-742-8718). Page charges will be assessed to defray printing costs. Registrants will receive a preprint volume at the meeting.

For further information, contact the Program Chairperson, Prof. Donald Johnson, Department of Meteorology, University of Wisconsin, 1225 W. Dayton St., Madison, WI 53706. (5/90)

\section{Special Session on Laser Atmospheric Studies, 13-18 January 1991, New Orleans, La.}

A Special Session on Laser Atmospheric Studies, sponsored by the American Meteorological Society, will be held during the 71st AMS Annual Meeting, 1318 January 1991, at the Hyatt Regency Hotel in New Orleans, La.

Papers were solicited on all aspects of atmospheric lidar measurements. Oral and poster sessions are planned, including the possibility of joint sessions with the Seventh AMS Symposium on Meteorological Observations and Instrumentation or the Seventh Joint Conference on Applications of Air Pollution Meteorology with AWMA.

The deadline for abstracts has passed. AMS will provide instructions, deadline information, and special typing paper to authors of accepted papers. Complete, camera-ready manuscripts not more than six pages in length must be submitted by 1 October 1990 to AMS headquarters. Page charges will be assessed to defray printing costs. A volume of extended abstracts will be distributed at the meeting. If a small number of papers is submitted, they may be published jointly with appropriate conference preprint volume; otherwise, a separate volume will be distributed.

For further information, contact the Program Chairperson, Edwin W. Eloranta, Dept. of Meteorology, Univ. of Wisconsin, 1225 W. Dayton, Madison, WI 53706 (tel.: $608-262-7327$ or 262-2828). (5/90)

\section{Call for Papers}

III Conference on Modeling of Rainfall Fields: Hydrologic and Meteorological Aspects, February 27-March 1, 1991, College Station, Tex.

The III Conference on Modeling of Rainfall Fields: Hydrologic and Meteorological Aspects will be held 27 February-1 March 1991 at the College Station Hilton and Conference Center, College Station, Texas. Texas A\&M will serve as host for the meeting, which will be supported by NSF and NASA and cosponsored by the American Meteorological Society and the American Geophysical Union.

The use of remote sensors of precipitation and their effects on the modeling and forecast of the rainfall process were widely discussed during the first two conferences in 1986 and 1988 . To apply remote sensors, usually a stochastic approach to the precipitation process has to be carried out, something that the hydrologic community has been doing for a long time. On the other hand, models of the precipitation process, which have been developed by hydrologists, were presented at the last Conference, and these models have more physical basis than previous ones. This proves that the interaction among the two groups is growing and that a "candid interchange" of ideas among meteorologists and hydrologists is very productive for both fields.

The Texas Institute of Oceanography Symposium on Measurement of Rainfall from Space will held during the two days (25-26 February) prior to the Conference and will emphasize the remote sensing part of precipitation modeling. In this Symposium, invited speakers will present the state of the art on remote sensing of rainfall. Participants to the Conference are also invited to participate in the Symposium. We are confident that enough new research material on precipitation modeling will be available at that time, 
and the Conference will be fruitful.

It is expected that around 30-35 papers will be presented, both invited and submitted. Preliminary versions of the papers should be submitted before 15 October 1990 to Prof. Gerald R. North, Climate System Research Program, College of Geosciences, Texas A\&M Univ., College Station, TX 77843-3146 (tel.:409-845-8583) or Prof. Juan B. Valdes, Dept. of Civil Engineering, Texas A\&M Univ., College Station, TX 77843-3136 (tel.: 409-845-1340; fax: 409-8456156; jbv1464@tamsigma.BITNET).

Registration will be set at $\$ 80$ per person. Bryan and College Station are adjoining medium-size cities with sufficient lodging and moderate prices. Campus lodging is also available, but the number of rooms is limited.

For further information contact Prof. North or Prof. Valdes at the addresses above. (8/90)

\section{Call for Papers}

\section{Tornado Symposium III, April 2-5, 1991, Norman, Okla.}

The Tornado Symposium III will be held 2-5 April 1991 in Norman, Oklahoma. It will occur on the 16th anniversary of the Jumbo Outbreak and will commemorate the appointment by the Univ. of Chicago of Dr. T. T. Fujita as Merriam Distinguished Professor. The meteorological community in Norman, including the NSSL, the OKC NWS Forecast Office, the NEXRAD Operational Support Facility, and the University of Oklahoma School of Meteorology, Oklahoma Climatological Survey, CIMMS, and the Center for Analysis and Prediction of Storms will serve as hosts for the symposium. The American Meteorological Society is one of a number of cosponsors.

There has been considerable improvement in our basic understanding of tornadoes and in operational and engineering applications of that understanding during the past 14 years. Now, the NWS is about to begin a wholesale modernization and restructuring program based on the introduction of new observing systems such as the WSR-88D (NEXRAD) radar, profilers, and GOES-Next. Furthermore, the research and operational communities are now planning the first field observation under the STORM program for sometime in the early 1990s. The Tornado Symposium III will review the advances of the last decade and focus on the opportunities about to unfold.

Each session will begin with an invited review paper, followed by other invited and contributed papers. The program committee, chaired by D. Burgess, R. Davies-Jones and C. Doswell, solicits contributed papers, especially from the operational community. There will be no poster sessions, but there will be "static" displays of hardware, software, photographs, videos, etc. to be set up near the meeting room for browsing during breaks.

The planned session topics are as follows: (1)
Tornado theory (including waterspouts, landspouts); (2) Numerical modeling; (3) Hurricane-spawned tornadoes; (4) Physical models and analogs; (5) Tornado forecasting (including characteristics of the environment); (6) Tornado detection and warning (including radar signatures and algorithms); (7) Tornado observations; (8) Damage surveys; (9) Climatology, Hazards, Risk Assessment; (10) Engineering for occupant safety; (11) Containment of hazardous material; (12) Building codes and standards.

After the presentations conclude at noon on 5 April, there will be three workshops: one on wind engineering aspects of damage assessment and control; one on numerical modeling of tornadoes and tornadic storms; and one on warning and preparedness.

Authors who may wish to contribute a paper should notify the program committee by 15 September 1990. The committee will accept abstracts, in standard AGU Format (copy available on request), until 1 December 1990. Instead of a preprint volume there will be a preprinted abstract volume (similar to those of the Fall and Spring Meetings of the AGU). The symposium proceedings, to include all papers presented and a transcript of any comments and replies during the presentations, will be published in a volume of the highest standards and quality, suitable for bibliographic reference.

For further information, contact $\mathrm{C}$. Doswell (tel.:405-366-6683;FTS763-6683; Internet CDOSWELL @nssl.gcnuoknor.edu) or W. Beasley (tel.405-3253041; Internet WBEASLEY@geoadm.gcn.ouknor.edu; OMNET: W.BEASLEY; AGU/KOSMOS: WBEASLEY). $(8 / 90)$

\section{1th Conference on Fire and Forest Meteorology, April 16-19, 1991, Missoula, Mont.} The 11th Conference on Fire and Forest Meteorology, sponsored by the Society of American Foresters and the American Meteorological Society, and cosponsored by the USDA Forest Service Intermountain Research Station and the Univ. of Montana School of Forestry, will be held 16-19 April 1991 at the Holiday Inn in Missoula, Montana.

The theme of the conference is Computer Applications in Research and Management. Papers are solicited in the areas of remote sensing and GIS, fire and atmospheric interactions, ecosystem modeling and quantitative ecology, climate change and fire severity, and large-scale fire behavior. Contributions are also solicited on traditional subjects such as fire meteorology and climatology; inventory, modeling, and prediction of fuel properties and fire potential; and effects of fire on air, soil, water and vegetation.

Sessions will be structured to permit both oral and interactive poster presentations. Papers will be published in proceedings without reference to method of presentation.

The deadline for abstracts has passed. Authors will receive notification of acceptance and instructions 
for preparing camera-ready papers on or about 15 September 1990. Draft final papers are due on 15 February 1991 for review of format and layout. Final papers are due at the meeting.

For further information, contact Patricia L. Andrews, USDA Forest Service, Intermountain Fire Sciences Lab., PO Box 8089, Missoula, MT 59807 (tel.: 406329-4827; FTS: 584-4827; fax: 406-329-4863; DG address: P.ANDREWS:S22L01A) or Donald F. Potts, School of Forestry, Univ. of Montana, Missoula, MT 59812 (tel.: 406-243-6622; fax: 406-243-4510). (6/90)

\section{Third Topical Meeting on Emergency Preparedness and Response, April 16-19, 1991, Chicago, III.}

The Third Topical Meeting on Emergency Preparedness and Response, sponsored by the American Nuclear Society and cosponsored by the American Meteorological Society, will be held 16-19 April 1990 at the McCormick Center Hotel, Chicago, Illinois.

The Meeting will present improvements in the sciences and technologies necessary to rapidly assess and mitigate the consequences of accidental releases of both nuclear and non-nuclear pollutants to the environment. Both invited and contributed papers will be presented in oral and poster sessions. Contributed papers are solicited on the following topics: Emergency Response Programs; Instrumentation; Impacts of Next Generation Reactors on Emergency Preparedness; Source Term Characterization; Environmental Models and Evaluation; Implementation of Radiation Protection Standards; Communication Systems; Environmental Sampling; Integration of Modeling and Environmental Sampling; Radiological and Non-radiological Experiences; Transportation and Radioactive Source Accidents; Emergenćy Response Training and Exercises; Agencies and Commercial Interfaces; Integration of Nuclear and Non-nuclear Preparedness; International Issues; Data Management and Information Processing; Public Information and Its Management; Post-accident Clean-up and Waste Management; Financial Issues.

The deadline for abstracts has passed. Authors will be notified of abstract acceptance and will receive instruction kits for manuscript preparation by 1 November 1990 . The deadline for receipt of finished manuscripts is 4 January 1991.

For further information, contact Dr. Charles Miller, Technical Program Chairperson, Illinois Dept. of Nuclear Safety, 1035 Outer Park Drive, Springfield, IL 62704 (tel.: 217-785-9889; fax: 217-782-9762). (8/90)

\section{Call for Papers}

19th Conference on Hurricanes and Tropical Meteorology, May 6-10, 1991, Miami, Fla.

The 19th Conference on Hurricanes and Tropical Meteorology, sponsored by the American Meteorological Society, will be held 6-10 May 1991 (note change of date) at the Biscayne Bay Marriott in Miami, Florida, in conjunction with the Fifth Conference on Meteorology and Oceanography of the Coastal Zone.

Papers on all aspects of tropical meteorology are invited. Special review sessions are planned on the topics of the theory of tropical cyclone motion and on the Office of Naval Research tropical cyclone motion field experiment. A joint session on Storm Surge is planned.

Titles and reviewer's abstracts (200-400 words) should be sent to the Program Chairperson, Miles Lawrence, National Hurricane Center, 1320 S. Dixie Highway, Coral Gables, FL 33146 (tel.: 305-6664612; fax: 305-665-8526) no later than 1 October 1990. Please include author's name(s), complete mailing address, and telephone/fax numbers. Only one paper will be accepted from each lead author. Authors should indicate whether their paper is suitable for a poster session.

Authors of selected papers will be notified by 21 October 1990 and will receive special typing paper and instructions on how to prepare an extended abstract for the conference proceedings. Page charges will be assessed to help defray costs of preprint volumes. Camera-ready extended abstracts are due by 7 January 1991 at AMS headquarters.

A certificate and prize of $\$ 100$ may be awarded at the conference for the best student paper, based on content and presentation. Students or recent graduates wishing to compete must be the sole author and should indicate their desire to compete when submitting an abstract. The Banner I. Miller Award will also be awarded, if appropriate, for the best published paper on hurricane and tropical weather forecasting for the period July 1988 through June 1990. (5/90; r7/90; r8/ 90)

\section{Call for Papers}

Fifth Conference on Meteorology and Oceanography of the Coastal Zone, May 610, 1991, Miami, Fla.

The Fifth Conference on Meteorology and Oceanography of the Coastal Zone, sponsored by the American Meteorological Society, will be held 6-10 May 1991 (note change of date) at the Biscayne Bay Marriott in Miami, Florida, in conjunction with the 19th Conference on Hurricanes and Tropical Meteorology. The technical program is being arranged by a special program committee established by the AMS Committee on Meteorology and Oceanography of the Coastal Zone.

The purpose of the conference is to exchange information on the science and technology of meteorological and related ocean processes in coastal zones. The conference will consist largely of submitted papers and a few invited papers. In addition, submitted papers will be accepted for presentation in poster format, with a brief synopsis at a general session, as 
well as for joint sessions with the coincident conference.

Papers are solicited on all aspects of the meteorology and oceanography of the coastal and offshore areas. Interdisciplinary research involving both meteorology and oceanography is encouraged. It is intended that the conference will include sessions covering such topics as the prediction of winds, waves, ice, fog and coastal storms; observations of meteorological and oceanographic structure including topographically forced circulations, land and sea breezes, coastal micrometeorology, coastal sea surface temperature studies, coastal currents, coastal ocean dynamics, cross shelf exchange processes, oceanatmosphere coupling, automatic observing systems and numerical modeling techniques. Research papers which describe results from GUFMEX and SMILE are particularly encouraged, as are papers for a special session devoted to the HEXMAX experiment.

A copy of the title and a 200-400 word abstract should be submitted by 1 October 1990 to the Program Chairperson, Steven W. Lyons, Dept. of Meteorology, Texas A\&M University, College Station, TX 77843 (tel.: 409-845-3228; fax: 409-845-6331). Please include author's name(s), complete mailing address, and telephone/fax numbers.

A preprint volume will be produced and distributed at the conference. Camera-ready papers including diagrams and photos must be received at AMS headquarters no later than 7 January 1991. Page charges will be assessed to defray the cost of printing. $(5 / 90 ; r 7 / 90 ; r 8 / 90)$

\section{International Conference and Workshop on Modeling and Mitigating the Consequences of Accidental Releases of Hazardous Materials, May 20-24, 1991, New Orleans, La.}

The International Conference and Workshop on Modeling and Mitigating the Consequences of Accidental Releases of Hazardous Materials, organized by the American Institute of Chemical Engineers' Center for Chemical Process Safety, will be held 20-24 May 1991 (please note new date) at the Clarion Hotel in New Orleans, La. Joint sponsors are the American Meteorological Society, the U.S. Environmental Protection Agency, and Health and Safety Executive (United Kingdom).

The conference will focus on improved methods for predicting the consequences of accidental releases of toxic or flammable materials. Presentations will be made on the latest technology in hazardous vapor cloud source and dispersion modeling as well as in predicting the consequences of vapor cloud fires, explosions, and BLEVEs; the latest developments in mitigating the consequences of episodic releases of hazardous materials; and the practical use of models in safe plant design, operation and emergency preparedness. At the final session, attention will be turned to needed areas of research and development for improving predictive dispersion and mitigation techniques of hazardous releases.

For information on the plenary sessions, please refer to previous issues of the BULLETIN.

The deadline for abstracts has passed. Deadline for drafts of papers is 1 December 1990.

For further information, contact either the Program Chairperson, Rudy Diener, Exxon Research and Engineering, P.O. Box 101, Florham Park, NJ 07932 (tel.: 201-765-1633) or Sandy Schreiber, CCPS Staff, American Institute of Chemical Engineers, Center for Chemical Process Safety, 12th Floor, 345 East 47th St., New York, NY 10017 (tel.: 212-705-7727). (11/89; r3/90)

\section{Call for Papers}

\section{Symposium on the Tropospheric Chemistry of the Antarctic Region, June 3-6, 1991,} Boulder, Colo.

The Symposium on the Tropospheric Chemistry of the Antarctic Region will be held 3-6 June 1991 in Boulder, Colorado. The Symposium is sponsored by the International Global Atmospheric Chemistry Program (IGAC), CIRES/Univ. of Colorado, NOAA, AES Canada, and the National Science Foundation. The American Meteorological Society is a cosponsor of the Symposium.

The Symposium objective is to better understand the role of the southern high latitude troposphere in global change by reviewing the past and present composition and processes controlling composition and to plan a strategy for future research on this topic.

Topics to be highlighted are: (1) Aerosols and gases in the troposphere: sources, sinks, and occurrence; (2) Air-surface exchange; (3) Tropospherestratosphere exchange; (4) Ice-snow chemistry related to tropospheric composition and climate; (5) Chemistry and physics of clouds; (6) Role of meteorological processes. Three days will be dedicated to presentations and one day to discussions of future studies. Presentations will be invited and contributed. The proceedings of the meeting will be published in a dedicated issue of Tellus.

To affirm your participation, you should send a paper title by 3 October 1990 to Barry A. Bodhaine, Antarctic Symposium, NOAA-CMDL R/E/CG1, 325 Broadway, Boulder, CO 80303-3328 (tel.: 303-4976659; fax: 303-497-6290). One-page abstracts are due by 3 January 1991. Final papers must be submitted by 3 September 1991. (8/90)

\section{Call for Papers}

25th International Conference on Radar Meteorology, June 24-28, 1991, Paris, France The 25th International Conference on Radar Meteorology, sponsored by the American Meteorological Society and the Societe Meteorologique de France, 
and cosponsored by the World Meteorological Organization, will take place 24-28 June 1991 in Paris, France. The conference will be held in conjunction with the Fourth International Conference on Aviation Weather Systems (see following Call for Papers); several joint sessions are planned. The meetings will follow the Paris Air Show to be held 13-23 June 1991.

At the radar conference, special emphasis is being placed on the applications of radar to nowcasting, particularly the use of radar and radar networks to the detection, short-range forecasting, and diagnostic studies of the structure and kinematics of convective storms, organized mesoscale heavy-rain systems, tropical cyclones, winter storms, and severe weather. In addition, papers are encouraged that focus on applied research in the use of radar for hydrometeorology, forecasting and warning, and aviation safety.

Other proposed topics include the development of new techniques such as applications of polarization diversity, signal processing, tropospheric profilers, the emerging NEXRAD technology, and the combination of radar and other remotely sensed observations such as lightning ground-strike data. Also encouraged are papers dealing with basic research topics that utilize radar such as cloud scale and mesoscale circulations, microphysical and dynamical interactions in precipitating weather systems, and boundary layer processes.

In cooperation with the AMS Committee on Artificial Intelligence Applications to Environmental Science, the organizing committee invites abstracts dealing with applications of artificial intelligence concepts to the automated interpretation of radar data and to other aspects of radar meteorology.

Both oral and poster session are planned. Authors should indicate their preference for either format although every preference may not be accommodated. Poster sessions will be of equal status to oral presentations.

Because of the anticipated large number of submitted abstracts, submissions of more than one paper by the same author(s) are discouraged; acceptance, however, will be decided on a case-bycase basis.

Papers will be selected on the basis of a 200- to 400-word abstract that may include up to two key figures. Authors should indicate the originality of their approach, procedure and results, and convey the importance of the work. Failure to do so could result in rejection of the abstract.

Titles and abstracts should be sent not later than 15 October 1990 to either of the Program CoChairpersons: David Jorgensen at NOAA/NSSL/ Mesoscale Research Division, R/E/NS1, 325 Broadway, Boulder, CO 80303 (tel.: 303-497-6246; fax: 303-4976930; telex: 592811 NOAA MASC BDR; OMNET mail address: NSSL.MRD) or Marc Gilet at Direction de la Meteorologie Nationale, SETIM, BP-202, F-78195 Trappes Cedex, France (tel.: 33-1-30 5002 20; fax: 33-1-30 5099 89; telex: 842699727 F MTOTECH).

On their abstracts, authors must include their names, mailing address (of the corresponding author), telephone and fax numbers, and electronic mailing address (if available). Authors will be notified by 3 December 1990 regarding disposition of their abstracts.

Authors of accepted papers will receive instructions and special typing paper for submitting manuscripts. Complete, camera-ready manuscripts not more than four pages in length, including figures, must be submitted by 15 February 1991 to AMS headquarters, Attn.: Evelyn Mazur, 45 Beacon St., Boston, MA 02108 USA (tel.: 617-227-2425; fax: 617-742-8718). Page charges will be assessed to defray printing costs. Registrants will receive a preprint volume at the conference.

For further information, contact either of the Program Co-Chairpersons at the addresses and telephone numbers mentioned above. (9/89; r2/90; r5/90)

\section{Call for Papers}

\section{Fourth International Conference on Aviation Weather Systems, June 24-26, 1991, Paris, France}

The Fourth International Conference on Aviation Weather Systems, sponsored by the American Meteorological Society and the Societe Meteorologique de France, and cosponsored by the World Meteorological Organization, will take place 24--26 June 1991 in Paris, France, immediately following the Paris Air Show to be held 13-23 June 1991. The AMS Committee on Aviation, Range, and Aerospace is organizing the meeting, which will be held in conjunction with the 25th International Conference on Radar Meteorology, 24-28 June 1991 (see preceding announcement). Several joint sessions are being considered.

This conference will address all aspects of aviation meteorology including applications to general aviation, commercial aviation, flight test range, and aerospace operations. However, special emphasis will be placed on the use of Doppler radar and other new observing systems such as on-board, real-time observation platforms, wind profiling systems, wind shear detection systems, lightning detection systems and new satellite sensing systems. Papers focusing on the use of radar, especially Doppler radar, will be considered for the planned joint sessions. A separate session on the use of artificial intelligence and/or expert system techniques for forecasting phenomena important to aviation operations is also being planned.

Sessions will be developed around these major categories: (1) Detection Systems -- A comprehensive examination of meteorological observations relevant to aviation forecasting, including those that are groundbased, airborne and satellite; (2) Aviation Safety -- A concerted look at specific phenomena that represent hazards to aviation operations. This session will focus more on morphology and scientific understanding of the phenomena. Invited topics are wind shear, thunderstorm and icing regimes, along with winter 
storms, lightning, ceiling and visibility. All papers should clearly focus on the aviation hazards related to the phenomena; (3) Efficiency of Operations -- A focus on specific phenomena and forecast techniques that relate directly to the efficiency of aviation operations. Invited categories are flight level wind forecasting, numerical model applications, forecast center products, and specific weather information that affects terminal area operations; (4) Access to Weather Information -- Dissemination of weather information to specific aviation users including air traffic control facilities, industry dispatch facilities, range and space operation centers, and to the individual pilot; (5) Training and education -- Focus on special training initiatives, facilities, and programs that benefit the aviation community. Invited topics are training and education designed for aviation forecasters, training for pilots and training for specific user groups like dispatchers, tower personnel, and air traffic control center personnel.

Both oral and poster sessions are planned. Authors should indicate if a poster presentation is preferred. Papers will be selected by the program committee on the basis of a 300- to 700-word abstract, in English, that should include up to two key figures. Titles and abstracts must be received by the program committee no later than 15 October 1990 . Please include a complete mailing address, telephone number and electronic mailing address if available. Authors will be notified about the status of their paper by 1 December 1990. Complete, camera-ready manuscripts of not more than six pages in length, including figures, must be received at AMS headquarters by 15 February 1991. Page charges will be assessed to defray printing costs.

All abstracts should be mailed to Ms. Debbie Davis, Aviation Conference Program Coordinator, NCAR Research Applications Program, 2555 55th St., Boulder, CO 80301 . For more information, contact Ms. Davis at 303-497-8448 (fax:303-497-8401) or the Program Chairperson, Mr. Richard Wagoner, NOAA/ ERL, R/E/FS, 325 Broadway, Boulder, CO 803033328 (tel.: 303-497-6301; OMNET: R.WAGONER). $(1 / 90 ; r 5 / 90)$

\section{Call for Papers}

Fifth International Conference on Precipitation Scavenging and Atmosphere-Surface Exchange Processes, July 15-19, 1991, Richland, Wash.

The Fifth International Conference on Precipitation Scavenging and Atmosphere-Surface Exchange Processes will be held 15-19 July 1991 in Richland, Wash. The conference is being cosponsored by many organizations, including the American Meteorological Society.

The conference will emphasize measurements and models of scavenging and air-surface exchange processes for current and future applications.
One-page abstracts must be submitted not later than 15 October 1990 to the Conference CoChairperson, Dr. W. George N. Slinn, MS K6-78, Earth and Environmental Sciences Center, Pacific Northwest Laboratory, P.O. Box 999, Richland, WA 99352 USA (tel.: 509-375-4150; fax: 509-376-5368; telex: 15-2874).

Several review papers have been invited; a limited number of review papers are solicited. On their abstracts, authors should indicate a preference for either oral or poster session. Authors will be notified by 15 December 1990 regarding the disposition of their abstracts. Complete papers must be received by 15 April 1991, and camera-ready copies of papers, with appended responses to questions and comments from reviewers and attendees, will be due 15 October 1991.

For further information on sessions or travel support, please contact Dr. Slinn at the address above or see previous issues of the BULLETIN. Requests for travel grants must be received before 15 October 1990. (1/ 90; r4/90; 7/90)

\section{Call for Papers}

13th IMACS World Congress on Computation and Applied Mathematics, July 22-26, 1991, Dublin, Ireland

The 13th World Congress on Computation and Applied Mathematics of the International Association for Mathematics and Computers in Simulation (IMACS) will be held 22-26 July 1991, at Trinity College, Dublin, Ireland. The American Meteorological Society is a cooperating organization.

The Congress will include a session on Advances in Numerical Techniques for Integrating Atmospheric Models. Papers will be accepted on numerical techniques for global and limited area models. In the former category, both climate models and weather prediction models will be included.

One-page abstracts, representing original contributions or reviews, should be submitted no later than 15 January 1991 to the session chairman, Dr. J. R. Bates, NASA Goddard Space Flight Center, Code 611, Greenbelt, MD 20771 (tel.: 301-286-7482).

General information about the Congress can be obtained by contacting Ms. Paulene McKeever, IMACS '91, 40 Millview Lawns, Malahide, Co. Dublin, Ireland (tel.: 353-1-452081). (7/90)

\section{IUGG XX General Assembly, Aug. 11-24, 1991, Vienna, Austria}

The 20th International Union of Geodesy and Geophysics (IUGG) General Assembly will be held 11-24 August 1991 in Vienna, Austria. The American Meteorological Society is a cooperating organization.

Topics to be discussed will include geodesy, seismology, physics of the earth's interior, 
geomagnetism, meteorology, aeronomy, atmospheric physics, physical sciences of the ocean, hydrological sciences, vulcanology, and chemistry of the earth's interior.

AGU has applied to the National Science Foundation for a grant to assist the travel of individual U.S. scientists. In anticipation of favorable action by NSF, application forms for individual grants are available from: MP-IUGG, American Geophysical Union, 2000 Florida Ave., NW, Washington, DC 20009 (tel.: 202462-6900). The deadline for applications is 1 March 1991.

For further information, contact Prof. Peter Steinhauser, ZAMG, Hohe Warte 38, A-1190 Vienna, Austria (tel.: +43-222-36 4453 ext. 2001; telex: 131837 meteor; fax: +43-222-369 1233). (2/90; r8/90).

\section{Call for Papers}

\section{0th Conference on Agricultural and Forest Meteorology, September 10-13, 1991, Salt Lake City, Utah}

The 20th Conference on Agricultural and Forest Meteorology, sponsored by the American Meteorological Society, will be held 10-13 September 1991 at the Doubletree Hotel in Salt Lake City, Utah. The conference is being held in conjunction with the Tenth Conference on Biometeorology and Aerobiology and the Seventh Conference on Applied Climatology. (See following Calls for Papers.)

The program will include sessions on: (1) crop microclimate, (2) forest meteorology, (3) evapotranspiration and turbulent transfer within crop canopies, (4) operational agricultural weather forecasting, (5) applications of remote sensing in agriculture and forestry, and (6) crop models. A special session on hydrometeorology is also planned (see following call for papers). Joint sessions will be held with the other conferences.

Two copies of titles and a short (200-300 words) preliminary abstract of proposed papers should be submitted by 15 January 1991 to the Program Chairperson, Dr. Katharine B. Perry, Dept. of Horticulture, North Carolina State University, Box 7609, Raleigh, NC 27695-7609 (tel.: 919-737-3537) to be considered for acceptance. Authors must include full name and affiliation of all authors and the address and telephone number of the contact author. Authors should designate the topic area and one of the following: (1) submitted for consideration in oral session only, (2) submitted for consideration in poster session only, or (3) submitted for consideration in oral session but will accept poster session.

Authors of accepted papers will receive instructions and special typing paper in March, 1991 for preparation of a camera-ready manuscript for the conference preprint volume. The manuscripts, of no more than four pages, including diagrams, must be received at AMS headquarters no later than 15 May 1991 to be included in the preprint volume. Pages charges will be assessed to help defray printing costs. Attendees will receive a preprint volume at the time of registration. For more information about the technical program, contact Dr. Perry at the address above. (6/90)

\section{Call for Papers}

\section{Special Session on Hydrometeorology,} September 10-13, 1991, Salt Lake City, Utah The 20th Conference on Agricultural and Forest Meteorology will have a Special Session on Hydrometeorology sponsored by the AMS Committee on Hydrology. The Conference will be held 10-13 September 1991 at the Doubletree Hotel in Salt Lake City, Utah.

The Special Session will be devoted to the monitoring and modeling of the energy and water balance over areas from order 1 to $10^{4} \mathrm{~km}^{2}$ for both agricultural regions and natural ecosystems. It will emphasize the use of various techniques with satellite-, aircraft- and ground-based systems for quantifying hydrometeorological variables essential for estimating components of the energy and water balance (e.g., precipitation, evaporation, net radiation).

Specific topics include: (1) Investigations concerned with the potential of remote sensing in providing reliable estimates of input parameters for energy and water balance modeling. This will encompass experimental observations and modeling results from recent large scale interdisciplinary field experiments (e.g., FIFE and HAPEX); (2) Modeling the possible effects of large scale deforestation, desertification, etc., on the hydrologic cycle and subsequent feedbacks to regional climates; (3) Model simulations suggesting the effects of changes in global or regional near surface temperatures, atmospheric $\mathrm{CO}_{2}$ concentrations and regional precipitation patterns on available water supplies in different climatic zones.

Two copies of titles and a short (200-300 words) abstract of proposed papers should be submitted no later than 15 January 1991 to Dr. William P. Kustas, USDA-ARS Hydrology Lab., Bldg. 265 BARC-EAST, Beltsville, MD 20705 (tel.: 301-344-2498; fax: 301344-1931). Authors must include full name and affiliation of all authors and the address and telephone number of the contact author. Authors should designate the topic area and one of the following: (1) submitted for consideration in oral session only, (2) submitted for consideration in poster session only, or (3) submitted for consideration in oral session but will accept poster session.

Authors of accepted papers will receive instructions and special typing paper in March, 1991 for preparation of a camera-ready manuscript for the conference preprint volume. The manuscripts, of no more than four pages, including diagrams, must be received at AMS headquarters no later than 15 May 1991 to be included in the preprint volume. Page charges will be 
assessed to help defray printing costs. Attendees will receive a preprint volume at the time of registration including papers from the Special Session and the 20th Conference on Agricultural and Forest Meteorology.

For more information about the technical program, contact Dr. Kustas at the address above. (6/90)

\section{Call for Papers}

\section{Tenth Conference on Biometeorology and Aerobiology, September 10-13, 1991, Salt Lake City, Utah}

The Tenth Conference on Biometeorology and Aerobiology, sponsored by the American Meteorological Society, will be held 10-13 September 1991 at the Doubletree Hotel in Salt Lake City, Utah in conjunction with the 20th Conference on Agricultural and Forest Meteorology and the Seventh Conference on Applied Climatology.

The conference will emphasize biometeorological and aerobiological issues of the 21 st century, such as the effects of climatic change on human, animal, plant and insect ecology. The conference will include sessions on animal biometeorology, urban biometeorology, human biometeorology, insect biometeorology, aerobiology of pollens, fungal spores and plant aerosols, the effects of atmospheric physics on aerobiology, and biometeorological links with atmospheric circulation and climate models.

Papers will be solicited on all aspects of biometeorology and aerobiology. In addition, review papers are planned that will emphasize recent advances and future opportunities in biometeorology and aerobiology.

Acceptance of papers will be based on a reviewer's abstract (approx. 500 words) which should include the primary procedures and results of the paper and the relevance of those results to the problems of biometeorology and aerobiology. Two copies of the reviewer's abstract should be sent no later than $\mathbf{1 5}$ January 1991 to the Program Chairperson, Dr. John K. Westbrook, U.S. Dept. of Agriculture, Agricultural Research Service, PO Box 748, Tifton, GA 317930748 (tel.: 912-387-2377; fax: 912-382-8092). The Program Chairperson and the appropriate Session Chairperson will review the abstract for acceptance. The complete address and telephone number should be included for the contact person of the abstract. Acceptance notices will be sent to all contributors.

Instructions and special typing paper will be furnished to the authors of accepted papers. Cameraready manuscripts of no more than eight pages including diagrams must be received at AMS headquarters no later than 15 May 1991 to be included in the preprint volume. Page charges will be assessed to help defray printing costs. Attendees will receive a preprint volume at the time of registration. For further information on the technical program, contact Dr. Westbrook at the address above. (6/90)

\section{Call for Papers}

Seventh Conference on Applied Climatology, September 10-13, 1991, Salt Lake City, Utah The Seventh Conference on Applied Climatology, sponsored by the American Meteorological Society, will be held 10-13 September 1991 at the Doubletree Hotel in Salt Lake City, Utah, in conjunction with the 20th Conference on Agricultural and Forest Meteorology and the Tenth Conference on Biometeorology and Aerobiology (see preceding calls for papers).

Papers will be considered on all aspects of Applied Climatology, but special consideration will be given to papers in the following areas: (1) methods of using climatological information in a climate which may be changing; (2) socio-economic and biophysical impacts of major climate events including climate change; (3) climatological applications (or potential applications) of new measurement techniques, including both spacebased and surface-based observations; and (4) the interpretation of GCM model as related to problems in applied climatology. Review papers are encouraged.

Acceptance of papers will be based on an abstract of no more than 500 words. In addition to discussing the primary methods and results, the abstract should describe why the paper is an important contribution. Two copies of the abstract should be sent to the Program Chairperson, Thomas R. Karl, Global Climate Lab., National Climatic Data Center, Federal Building, Asheville, NC 28801 (tel.: 704-259-0319; fax: 704259-0246), no later than 15 January 1991. The Program Chairperson and the Session Chairperson will review the abstract for acceptance. Authors must include full name and affiliation of all authors and the address and telephone number of the contact author. Authors should designate whether the paper falls into one of the above four topics or whether it is a review paper. If neither of these is appropriate, no designation is needed. Acceptance notices will be sent to all contributors.

Instructions and special typing paper will be furnished to the authors of accepted papers. Cameraready manuscripts of extended abstracts of no more than two pages must be received at AMS headquarters no later than 15 May 1991 to be included in the preprint volume. Page charges will be assessed to help defray printing costs. Participants will receive a preprint volume at the time of registration. For further information on the technical program, contact Tom Karl at the address above. $(6 / 90 ; r 7 / 90)$

\section{Call for Papers}

\section{Eighth Conference on Atmospheric and Oceanic Waves and Stability, October 1991, Denver, Colo.}

The Eighth Conference on Atmospheric and Oceanic Waves and Stability, sponsored by the American 
Meteorological Society and organized by the AMS Committee on Atmospheric and Oceanic Waves and Stability, will be held in October 1991 in Denver, Colo. The conference will be held in conjunction with the Ninth Conference on Numerical Weather Prediction and the Fifth Conference on Climate Variations (see following calls for papers).

These conferences will be held concurrently to promote a greater exchange of research findings and viewpoints in areas of atmospheric sciences that are concerned with atmospheric/oceanic dynamics and prediction. It is planned to have (1) a half-day joint session with the Ninth Conference on Numerical Weather Prediction with the theme "Moist Atmospheric Dynamics and Forecasting;" (2) a joint session with the Fifth Conference on Climate Variations with the theme "Theory and Prediction of Interannual Variability;" and (3) two joint sessions with both conferences with the themes "Role of Oceans in Weather and Climate" and "Tropical and Extratropical Intraseasonal Variability."

The remaining part of the waves and stability conference provides a forum for the discussion of basic problems in the fluid dynamics of atmospheres and oceans. Contributions in all areas of atmospheric and oceanic dynamics will be considered. Examples include the new development of linear instability theories, stormtracks, gravity wave dynamics, convection, and turbulence. Papers concerning geophysical dynamics of spatial and temporal scale interactions will be particularly welcome.

This meeting is planned to comprise poster sessions, invited talks and contributed oral presentations. In order to facilitate the presentation of as many viewpoints as possible, the program committee may limit the number of oral presentations to one per author.

Titles and abstracts (250 words maximum, doublespaced) should include the author's name, affiliation and telephone/fax numbers. If a poster session is preferred, please indicate so. Abstracts for the general sessions of Waves and Stability should be submitted no later than 1 February 1991 to the Program Chairperson, Prof. Mankin Mak, Dept. Atmos. Sci., Univ. of Illinois, 105 S. Gregory St., Urbana, IL 61801 (tel.: 217-333-2046; fax: 217-244-4393). Abstracts for the joint sessions mentioned above may be submitted to one of the three Program Chairpersons also no later than 1 February 1991.

Instructions and special typing paper will be furnished to authors of accepted papers. Cameraready manuscripts must be received at AMS headquarters no later than 15 June 1991 to be included in the preprint volume. Page charges will be assessed to defray printing costs.

For more information, contact the Program Chairperson, Prof. Mankin Mak at the above address. $(3 / 90 ; r 7 / 90)$

\section{Call for Papers}

Ninth Conference on Numerical Weather Prediction, October 1991, Denver, Colo.

The Ninth Conference on Numerical Weather Prediction, sponsored by the American Meteorological Society and organized by the AMS Committee on Weather Analysis and Forecasting, will be held in October 1991 in Denver, Colo. The conference will be held in conjunction with the Eighth Conference on Atmospheric and Oceanic Waves and Stability (see preceding call for papers) and the Fifth Conference on Climate Variations.

These conferences will be held concurrently to promote a greater exchange of research findings and viewpoints in closely related areas of atmospheric sciences. Several joint sessions will be planned for that purpose.

Papers will be solicited on all aspects of numerical weather prediction. Sessions are expected to be held on the following areas: (1) analysis, quality control, initialization, and data assimilation; (2) limited-area and mesoscale models; (3) medium-range and extended-range forecast models; (4) numerical methods; (5) modeling of physical processes, including convective, radiative, and boundary-layer processes; (6) orographic effects; (7) synoptic/diagnostic studies with application to NWP; (8) observing system and observing system simulation experiments; (9) numerical model-based forecasting of sensible weather, including that by model output statistics; (10) numerical forecasting of severe weather; (11) forecast verification; and (12) climate modeling.

This is a preliminary announcement; further details will appear in future issues of the BULLETIN For more information, contact the Program Chairperson, Dr. Ying-Hwa Kuo, NCAR, P.O. Box 3000, Boulder, CO 80307 (tel.: 303-497-8910; fax: 303-497-8701). (3/90)

\section{Call for Papers}

\section{Fifth Conference on Climate Variations, October 1991, Denver, Colo.}

The Fifth Conference on Climate Variations, sponsored by the American Meteorological Society and organized by the AMS Committee on Climate Variations, will be held in October 1991 in Denver, Colo. The conference will be held in conjunction with the Ninth Conference on Numerical Weather Prediction and the Eighth Conference on Atmospheric and Oceanic Waves and Stability (see preceding calls for papers).

These conferences will be held concurrently to promote a greater exchange of research findings and viewpoints in closely related areas of atmospheric sciences. Several joint sessions will be planned for that purpose.

Papers will be solicited on all aspects of climate variations. Sessions will be expected in the following 
areas: (1) detection and modeling of global climate change; (2) observations and impacts of regional climate changes; (3) cloud/radiation/dynamics interactions; (4) diagnostic and modeling studies of interannual and intraseasonal fluctuations in the atmosphere and oceans; (5) modeling of the coupled climate system; (6) climate predictability and predictions; and (7) paleoclimate variations.

Titles and abstracts ( 250 words maximum, doublespaced) should include the author's name, affiliation and telephone/fax numbers. If a poster session is preferred, please indicate so. Abstracts should be submitted no later than 1 February 1991 to the Program Chairperson, Dr. William K.-M. Lau, Laboratory for Atmospheres, NASA/Goddard Space Flight Center, Code 913, Greenbelt, MD 20771 (tel.: 301-286-6772; fax: 301-286-4804).

Instructions and special typing paper will be furnished to authors of accepted papers. Cameraready manuscripts must be received at AMS headquarters no later than 15 June 1991 to be included in the preprint volume. Page charges will be assessed to defray printing costs.

For more information, contact Dr. Lau at the above address. ( $3 / 90 ; r 7 / 90)$

\section{Call for Papers}

First International Conference on Broadcast Meteorology, June 17-21, 1991, London, England

The First International Conference on Broadcast
Meteorology, jointly sponsored by the American Meteorological Society and the Royal Meteorological Society, and cosponsored by the World Meteorological Organization, will be held 17-21 June 1991 in London, England. This meeting will also be the 21st AMS Conference on Broadcast Meteorology.

Conference papers are being solicited on technological advances and historical perspectives of weathercasting; television management and consultant philosophies and recommendations; and reviews of the past year's major weather events. Sessions are also planned on the Decade of Natural Disaster Reduction, Global Warming, and Science Education. International video and audio tapes of weathercasters are solicited. Arrangements will be made for touring the British Broadcasting Corporation (BBC) in London and the British Meteorological Office in Bracknell.

Plans include exhibit space for commercial and educational displays. Details, including exhibit fees, will be determined after site selection has been made. Contact AMS, who will furnish information as soon as it is available.

Two copies of abstracts from authors residing in the U.S. or Canada should be sent to Roy Leep, WTVT Television Weather Service, PO Box 31113, Tampa, FL 33631-3113 (tel.: 813-870-9694; fax: 813-8727202). Two copies of abstracts from authors outside the U.S./Canada should be sent to Jim Bacon, Meteorologist, Anglia Television Limited, Anglia House, Norwich NR1 3JC, United Kingdom (tel.: 0603-615151; fax: 0603-631877). The deadline for abstracts is $\mathbf{3 0}$ November 1990. (9/90) 